\title{
Enterprise Mashups - Neue Herausforderung für das Projektmanagement
}

\author{
Volker Hoyer ${ }^{12}$ und Katarina Stanoevska-Slabeva ${ }^{2}$ \\ ${ }^{1}$ SAP Research CEC, Blumenbergplatz 9, 9000 St. Gallen, Schweiz \\ ${ }^{2}$ Universität St. Gallen, Institut für Medien- und Kommunikationsmanagement, \\ Blumenbergplatz 9, 9000 St. Gallen, Schweiz \\ email: volker.hoyer@sap.com, katarina.stanoevska@unisg.ch
}

\begin{abstract}
Eine neue Generation von Webapplikationen verändert die Softwareentwicklung und -anwendung grundlegend. Neue Entwicklungen, bekannt unter dem Begriff Enterprise Mashups, ermöglichen es Endnutzern, auf Basis existierender Webressourcen individuelle Applikationen innerhalb von Minuten zu erstellen. Nicht mehr alleine die ITAbteilung ist dabei für die Erstellung der Unternehmensapplikationen zuständig, sondern die Endnutzer stellen sich entsprechend ihren kontinuierlich veränderten Bedürfnissen ihre eigenen Arbeitsumgebungen im Browser zusammen. Aus Perspektive des ITManagements impliziert diese individuelle Softwareherstellung und -anwendung neue Anforderungen hinsichtlich des Projektmanagements.
\end{abstract}

\section{Inhaltsverzeichnis}

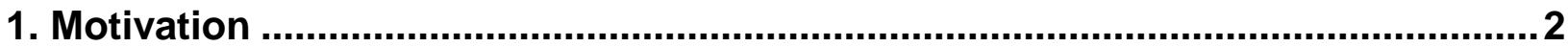

2. Enterprise Mashup Stack.................................................................................. 2

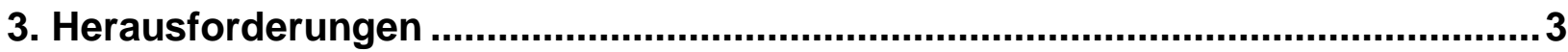

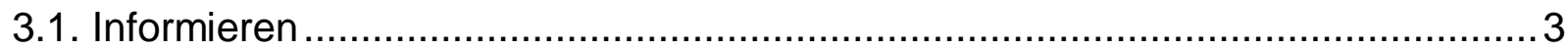

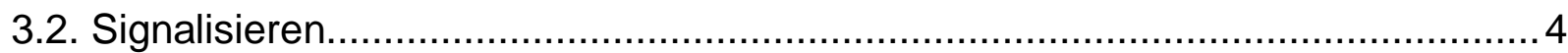

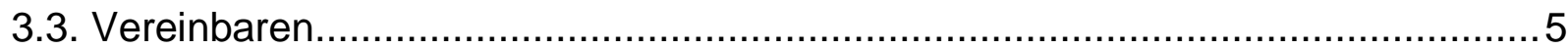

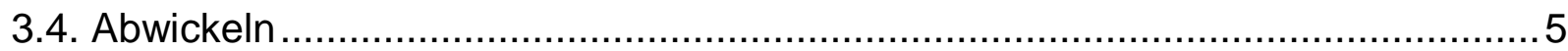

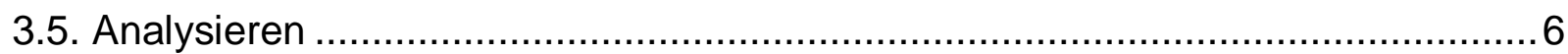

4. Managementmodel für Enterprise Mashups ......................................................6

5. Zusammenfassung und Ausblick ...................................................................... 7

6. Referenzen ........................................................................................................... 8 